\title{
Posterior Reversible Encephalopathy Syndrome (PRES) Following Alcohol Induced Disulfuram Toxicity
}

\author{
Dr. Srikrishna Nukala ${ }^{1}$, Dr. Venkata Kiran Vaddadi ${ }^{2}$ \\ ${ }^{1}$ (Assistant Professor, Department of Psychiatry, GSL Medical College, Rajahmundry, Andhra Pradesh, India) \\ ${ }_{2}^{2}$ (Post Graduate, Department of Psychiatry, GSL Medical College, Rajahmundry, Andhra Pradesh, India)
}

\begin{abstract}
Posterior Reversible Encephalopathy Syndrome (PRES) is a clinico radiological entity. Symptomatology includes cognitive and behavioural disturbances, blurred vision, seizures, headache, vomiting. MRI reveals edematous changes in white and grey matter of brain. The most common etiology of PRES is Hypertensive encephalopathy, Eclampsia, Preeclampsia, Immunosuppressant drugs and cytotoxic drugs. PRES is usually reversible and the treatment is based on the management and withdrawal of the triggering factor.

We report a case of PRES, occurred after consuming alcohol while on Disulfuram which is a rare etiological entity.
\end{abstract}

Keywords: Cortical Blindness, Disulfuram and alcohol induced PRES, Focal neurological signs.

\section{Introduction}

Posterior reversible encephalopathy syndrome (PRES) $[1,2]$ is a clinico radiological entity that was well described by Hinchey et al. [3]. This condition has been designated by variety of names (Reversible posterior leukoencephalopathy syndrome, Reversible posterior cerebral edema syndrome, and Reversible occipital parietal Encephalopathy). PRES is now the accepted term [1,2,4]. The clinical hallmark of PRES is headache, confusion, seizures, cortical blindness and focal neurological signs and a diagnostic Magnetic resonance imaging picture.

PRES can develop in association with vast array of conditions most common being exposure to Toxic agents $11 \%$ [5] to $61 \%$ [6]. Hypertension 6\% [7] to 72\% [5], Preeclampsia/Eclampsia 7\% [6] to 20\% [3]. Autoimmune diseases 8\% [6] to $10 \%$ [7].

Early recognition and treatment of this syndrome is important to prevent permanent neurological deficit. The treatment is based on the management or withdrawal of the triggering factor.
1. Introduction
2. Case Report
3. Figures
4. Discussion
5. Conclusion
6. Acknowledgements

II. Headings

\section{Case Report}

A 68-year-old man with history of alcoholism from past 45 years and increased consumption from past 6 months was admitted by his wife for de-addiction. He was inpatient for 20 days and was discharged with Tab Disulfuram $250 \mathrm{mg}$ BD.

2 days later the patient landed in casualty in acute confusional state, vomitings, headache, seizuresGTCS type. His blood pressure was $160 / 100 \mathrm{~mm}$ of $\mathrm{Hg}$, pulse rate was $90 / \mathrm{min}$, afebrile, and pupils were unequal in size and sluggishly reacting to light. Wife stated that the above symptoms appeared 2-3 hours after taking the morning dose of Disulfuram followed by alcohol consumption.

On neurological examination, patient was in acute confusional state, cortical blindness, areflexia, dysesthesias with burning pain, and weakness of both upper limbs and lower limbs, GCS score-7 (E-3, M-1, V3), fundoscopy was normal and did not reveal any papilledema or hypertensive retinopathy. Blood glucose RBS $-211 \mathrm{mg} / \mathrm{dl}$, serum calcium was $5.1 \mathrm{mg} / \mathrm{dl}$, with raised hepatic enzymes SGOP $-106 \mathrm{mg} / \mathrm{dl}$, SGPT $-111 \mathrm{mg} / \mathrm{dl}$ and ALP $-116 \mathrm{mg} / \mathrm{dl}$. CSF analysis was normal. Urine for porphyrinogen was negative. Serum magnesium was normal, serum potassium, sodium was normal, blood urea and creatinine was normal. CT scan Brain was normal.

MRI Brain (FLAIR) revealed High signal intensities on T2 weighted image, which were more prominent in parieto-occipital regions suggestive of Posterior reversible encephalopathy syndrome. Tab disulfuram was stopped and the patient was treated with anti convulsants, multivitamins and IV fluids. The next day the blood pressure was $130 / 80 \mathrm{~mm}$ of $\mathrm{Hg}$; pulse rate was $80 / \mathrm{min}$ with no further seizures. 
After 15 days of treatment patient showed signs of improvement. He was fully oriented to time, place and person, and was able to walk few steps with assistance and did not show any focal neurological signs. 21 days later he was able to walk without any assistance. Follow up MRI on day 21 showed marked reduction of the former signal hyper intensities in the posterior region, but now then patient was clinically asymptomatic.

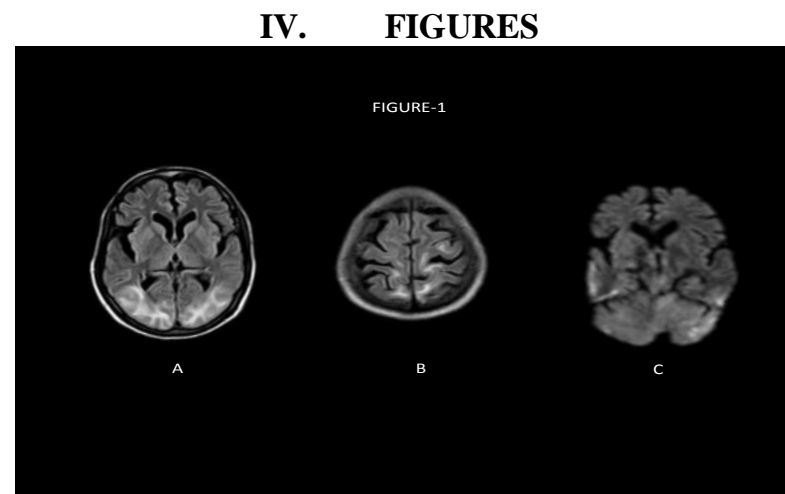

Fig-1: (A) \& (B) are T2 weighted Flair images showing Multiple Hyper intensities diffusely involving cortex and white matter of bilateral Parieto-occipital lobes. (C) Shows restriction of diffusion in the form of Hyper intensities seen at similar areas on DWI

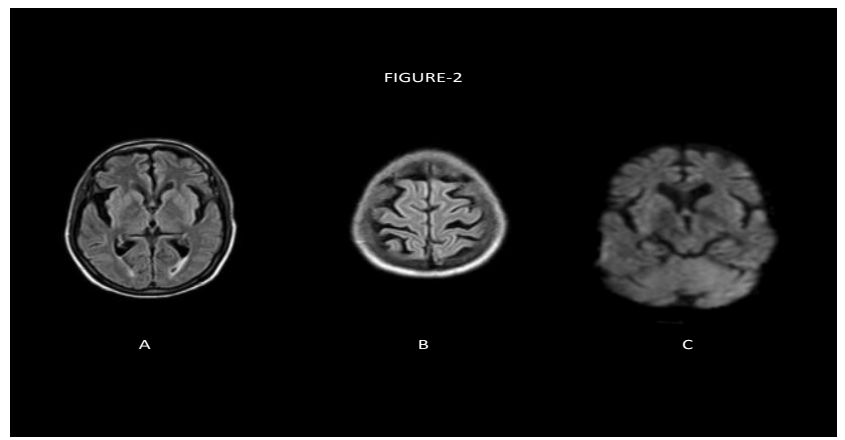

Fig-2: There is complete resolution of the Hyper intensities seen at bilateral Parieto-occipital lobes on T2 weighted Flair images (A) (B) and DWI (C) taken after 21days.

\section{Discussion}

The pathophysiology of PRES remains controversial. The two main hypotheses are:

1. Impaired cerebral auto regulation responsive for increased cerebral blood flow.

2. Endothelial dysfunction with cerebral hypo perfusion.

Under both hypotheses the result of cerebral blood perfusion abnormalities is Blood Brain Barrier dysfunction with cerebral vasogenic edema (2). In this case the most probable cause could be the active metabolites of Disulfuram; Diethyledithiocarbamate (DDC) and its metabolite Carbon disulfide (CS2) might have caused direct cytotoxic affect on the blood vessel wall damaging the vascular endothelium causing blood brain barrier dysfunction and cerebral vasogenic edema. As no other possible etiological factors responsible for PRES were found in this case, the diagnosis of PRES following alcohol induced disulfuram toxicity was made.

\section{Conclusion}

This is a clinically frightening syndrome which when not diagnosed early results in persistent deficits. Most patients have suggestive combination of symptoms; MRI is crucial for diagnosing, monitoring the course and assessing treatment effectiveness. The pathophysiology of PRES remains controversial however; the list of conditions known to be associated with PRES is increasing steadily. Early recognition and identifying underlying cause is the keystone of management.

\section{Acknowledgements}

Dr. Manasa Karri, Post Graduate, Department of Psychiatry, GSL Medical College and General Hospital, Rajahmundry.

For the Radiological guidance and support,we thank,

Dr. Anindita Mishra, M.D., Associate Professor, Department of Radiology, GSL Medical College and General Hospital, Rajahmundry.

Dr. MytriPriyadarshini, Post Graduate in Radiology, GSL Medical College and General Hospital, Rajahmundry. 
We extend our thanks to,

Dr. M. SrihariBabu, M.D., Associate Professor, Department of Medicine, GSL Medical College and General Hospital, Rajahmundry.

Dr. K. Komali, Post Graduate in Medicine, GSL Medical College and General Hospital, Rajahmundry.

\section{References}

[1] Bartynski WS. Posterior reversible encephalopathy syndrome, part 1: fundamental imaging and clinical features. AJNR Am J euroradiol 2008;29:1036-42.

[2] Bartynski WS. Posterior reversible encephalopathy syndrome, part 2: controversies surrounding pathophysiology of vasogenic edema. AJNR Am J Neuroradiol 2008;29: 1043-49.

[3] Hinchey J. Chaves C, Appignani B, et al. A reversible posterior leukoencephalopathy syndrome. N Engl J Med 1996;334:494-500.

[4] Casey SO, Sampaio RC, Michel E, Truwit CL. Posterior reversible encephalopathy syndrome: utility of fluid-attenuated inversion recovery MR imaging in the detection of cortical and subcortical lesions. AJNR Am J Neuroradiol 2000;21:1199-1206.

[5] Lee VH, Wijdicks EF, Manno EM, Rabinstein AA. Clinical spectrum of reversible posterior leukoencephalopathy syndrome, Arch Neurol 2008;65:205-10

[6] McKinney AM, Short J, Truwit CL, et al. Posterior reversible encephalopathy syndrome: incidence of atypical regions of involvement and imaging findings. AJR Am J Roentgenol 2007;189:904-12.

[7] Bartynski WS, Boardman JF, Zeigler ZR, Shadduck RK, Lister J. Posterior reversible encephalopathy syndrome in infection, sepsis and shock. AJNR Am J Neuroradiol 2006;27:2179-90. 